\title{
THE ROLE OF QUADRICEPSPLASTY IN TREATMENT OF POST-TRAUMATIC STIFF KNEE USING JUDET PROCEDURE
}

\author{
Thamer A Hamdan ${ }^{\circledR}$, Khalil I Sadek $^{*} \&$ Muwafaq S Mahde ${ }^{\#}$ \\ ${ }^{\circledR}$ FRCS, FICS, FACS, FRCP, American Board of Neurological \& Orthopedic Surgery, Professor of \\ Orthopedic Surgery. *MB,ChB, FICMS Orthopedic Surgeon, Basrah Teaching Hospital. "MB,ChB, \\ Basrah Teaching Hospital, Basrah, IRAQ.
}

\begin{abstract}
The lack of knee flexion is an increasingly recognized complication especially after trauma. This is a significant challenge for both surgeon and patients. In 1956, Judet proposed a quadricepsplasty technique that allow a graded release without the disruption of the vastus medialis, vastus lateralis, or rectus femoris.

The aim of this study is to evaluate the beneficial outcome of the Judet quadricepsplasty in improving the range of movement of knee joint in those patients complaining from posttraumatic stiffness.

This research was done for evaluating the clinical outcome of 15 patients who underwent a Judet's quadricepsplasty, they were 12 men and 3 women. The definitive flexion gain was classified according to Judet's criteria; excellent, if flexion was greater than $100^{\circ}$; good, from $80^{\circ}$ to $99^{\circ}$, fair result are from $50^{\circ}$ to $79^{\circ}$; and poor flexion degree is less than $50^{\circ}$. Patients were operated upon after an average of 19.40 \pm 17.63 months (range, 6-72 months) after first initial surgery. Average follow-up period was 6.5 \pm 3.6 months (range, 3-15 months). According to Judet criteria, 7 patients (47\%) achieved excellent, 5 patients (33\%) good, 2 patients (13\%) fair, with zero poor results. Final average flexion arc improvement was $97.67 \pm 18.6$ degrees with a range of 60-120 degrees. The noticed complications included; one case of extension lag excluded from the study and one case of small area of skin necrosis.

In conclusion, even though it was proposed in 1956, the Judet procedure seems to give a reproducible amount of good results today and still holds its leading role in the treatment of extra-articular knee stiffness.

Key words: Quadricepsplasty, Post-traumatic, Stiff joint, Knee joint, Judet procedure, Surgery
\end{abstract}

\section{Introduction}

$\mathrm{T}$ here are some joints, such as the wrist and ankle in which stiffness is compatible with excellent function. In the knee joint, however, any serious limitation of movement is a very considerable handicap and the patient may have to change both his job and his hobbies ${ }^{1}$. Traumatic causes of stiff knee include fractures of bone, inflammation of tendons or bursa, damage to the cartilage of the knee capsule or iatrogenic causes. Injuries may be sudden or may develop slowly over time ${ }^{2}$. Stiffness may follow either disease or trauma. When it is the result of infection or arthritis, attempts at restoring movement are not only disappointing but dangerous, and if any surgery at all is called for because of pain, instability, progressive deformity or for stiffness. When it follows trauma, however, the outlook is almost completely reversed and the most gratifying results can be obtained, even in the stiffest and most unpromising knees, by the operation of quadricepsplasty. This is in fact one of the most rewarding operations in the orthopedic surgeons repertoire, but one gets the impression 
that it is also one of the most neglected, simply because its possibilities are not sufficiently appreciated. Stiffness of the knee joint is one of the most common complications that presented after trauma or after surgical intervention in the thigh or that around knee, which can be treated by many surgical intervention one of these is the quadricepsplasty ${ }^{3}$.

\section{Patients and methods}

This prospective study was conducted in Basrah Teaching Hospital, Department Of Orthopedics. Fifteen patients suffering from post-traumatic knee joint stiffness were included in the study.

The total number of patients were 15 patients, 12 males and 3 females, with mean age of the patients was 35.60 years, range from 18 to 52 years. All patients were evaluated by a detailed history according to special questionnaire prepared for this purpose which include the pain (either in the knee, hip joint \& also back), limitation of daily activities (Affecting the ability to stand, to go up \& down stairs, squat \& dress), limping, deformity, instability, muscle atrophy \& secondary osteoarthritis .

Detailed information was taken regarding the cause, duration of the stiffness and the type of treatment for the previous problems including the history of osteomyelitis. Patients were asked about their past medical history; diabetes, rheumatologic diseases, and smoking. The range of the flexion is measured when stationary arm of the goniometer was placed parallel to the long axis of the femur along a line extending from the greater trochanter to the lateral femoral condyle, and the movable arm was placed parallel to the long axis of the fibula, between the head of the fibula and the lateral malleolus, and also measured the thigh muscle girth (all patients were presented with muscle wasting). We explain for the patient that the quadricepsplasty is a major operation and the patients should accept a very slow return of active quadriceps extension. Most patients can expect improvement in range of motion of the knee after quadricepsplasty but should expect some quadriceps weakness for many months.

All patients were sent for hematological investigation, biochemical investigation, and radiological examination for evaluating the state of the joint. Two units of blood usually prepared prior to surgery. Same surgeon performed the Judet's procedure for all of them.

Operative Technique: With the patient in supine position, first dose of antibiotics (Ceftriexone vial $1 \mathrm{gm}$ intravenously) was given with induction of anesthesia. The procedure was carried by direct lateral incision of the affected side and then by subvastus approach, the vastus lateralis was divided from the linea aspera; and the femoral bone was exposed with the release of the medial, lateral retinacula and release of the adhesions in the suprapatellar gutter and between the patella and femoral condyles. Release of the vastus intermedius, which extend from the superior pole of the patella to the upper thigh which was then lifted off the anterior and lateral surfaces of the femur extraperiosteally.

The joint was flexed gradually (before removing the metal if present), till reaching a maximum degree of flexion. If the flexion still below $120^{\circ}$, multiple small radial incisions were done in the quadriceps muscle near the muscleotendenous junction to increase the knee flexion degree.

Measurement of the flexion degree and removal of the implant from the femur was done. After completing the procedure, a good homeostasis should be achieved \& two drains were left in the field. The fascia and skin were closed in flexion position, and a compressive wrap 
with bandage was applied from the toe to the thigh to decrease swelling. The extremity was immobilized in a splint in about 50 degrees less than the maximal flexion obtained at operation by anterior slab and elevation.

Post-operative measures: All the patients were kept on (Ceftriexone 1gm and Amikacin $500 \mathrm{mg}$ vial twice daily) for three days with analgesia. The drains were usually removed after 2 days and the dressing was changed in the 3rd postoperative day then the patients were discharged on oral antibiotics with suitable analgesics for one week.

After two weeks, we remove the stitches and start passive and active exercises for the quadriceps and hamstrings, which are of critical importance to the success of this procedure. The knee was kept in extension during night and is exercised during the day with active and activeassisted exercises, active straight leg raising, isometric quadriceps exercises, resistance exercises, and bicycling. Galvanic and thermal therapies were advised for all the patients from the third week postoperatively and continued for one month.

All the patients completed the follow-up for at least three months (range 6.5 \pm 3.61 months) with frequent visits to hospital every two to three weeks included measuring the degree of the flexion and advising the patients for physiotherapy specially quadriceps load bearing exercise for those patients who achieved more than $90^{\circ}$ of flexion.

Gentle manipulation with the patient under anesthesia after three months was required for two patients only who did not get more than $90^{\circ}$ of flexion.
Complications: One patient had a small area of skin necrosis at site of incision which was treated conservatively and another patient ended with extension lag (20 degrees) which also was treated conservatively by splint. We classify the patients into two groups according to the flexion degree that was measured preoperatively, group 1 (preoperative flexion $<30^{\circ}$ ) which included 10 patients and group 2 (preoperative flexion $>30^{\circ}$ ) which included 5 patients.

The ranges of the flexion were measured by using the goniometer and the final results were assessed according to the Judet's criteria; the definitive flexion gain was classified as excellent, good, fair, or poor. Excellent when $>100$ degrees, good when $>80<99$ degrees, fair when $>50$ degrees $<79$ degrees, and poor when $<50$ degrees. Patients were asked for the satisfaction from this operation whether they got a very good, good, fair, or got worse after the operation .

\section{Results}

The total number of patients were 15 (12 males and 3 females) with mean age 35.60 years (minimum 18 years and maximum 51 years). Ten patients $(70 \%)$ were presented with long duration of stiffness.

Table I show the summary of the study data that include serial number for each patient, age in years, gender, side, and if the patients had open or multiple injuries previously. Also it included the first types of the treatment, duration of this treatment and if the patients suffered from osteomyelitis and the second surgical interventions for each. 


\begin{tabular}{|l|l|l|l|l|l|l|l|l|l|}
\hline \multicolumn{7}{|c|}{ Table I: Summary of the study data } \\
\hline $\begin{array}{l}\text { Case } \\
\text { Age }\end{array}$ & Sex & $\begin{array}{l}\text { Side } \\
\text { R/L }\end{array}$ & $\begin{array}{l}\text { Open } \\
\#\end{array}$ & $\begin{array}{l}\text { Multi } \\
\text { injury }\end{array}$ & $\begin{array}{l}\text { First } \\
\text { treatment }\end{array}$ & Duration & OM & $\begin{array}{l}\text { Second } \\
\text { treatment }\end{array}$ \\
\hline 1 & 32 & $\mathrm{~m}$ & $\mathrm{~L}$ & $*$ & & $\begin{array}{l}\text { External } \\
\text { fixation }\end{array}$ & $4 \mathrm{mth}$. & $*$ & $\begin{array}{l}\text { Long } \\
\text { plate }\end{array}$ \\
\hline 2 & 50 & $\mathrm{f}$ & $\mathrm{R}$ & & & POP & $5 \mathrm{mth}$. & & \\
\hline 3 & 49 & $\mathrm{~m}$ & $\mathrm{~L}$ & & & $\begin{array}{l}\text { External } \\
\text { fixation }\end{array}$ & $3 \mathrm{y}$. & & \\
\hline 4 & 37 & $\mathrm{~m}$ & $\mathrm{R}$ & $*$ & & $\begin{array}{l}\text { External } \\
\text { fixation }\end{array}$ & $1 \mathrm{y}$ & & \\
\hline 5 & 27 & $\mathrm{f}$ & $\mathrm{L}$ & & & $\begin{array}{l}\text { Long } \\
\text { plat }\end{array}$ & $6 \mathrm{y}$ & & \\
\hline 6 & 18 & $\mathrm{~m}$ & $\mathrm{R}$ & & & POP & $4 \mathrm{mth}$. & $*$ & \\
\hline 7 & 25 & $\mathrm{~m}$ & $\mathrm{~L}$ & & & POP & $5 \mathrm{mth}$. & & \\
\hline 8 & 51 & $\mathrm{f}$ & $\mathrm{L}$ & & & POP & $6 \mathrm{mth}$. & & \\
\hline 9 & 42 & $\mathrm{~m}$ & $\mathrm{R}$ & & & $\begin{array}{l}\text { External } \\
\text { fixation }\end{array}$ & $3 \mathrm{mth}$. & $*$ & Plate \\
\hline 10 & 38 & $\mathrm{~m}$ & $\mathrm{~L}$ & & & L-plate & $2 \mathrm{y}$ & & \\
\hline 11 & 48 & $\mathrm{~m}$ & $\mathrm{R}$ & $*$ & $*$ & $\begin{array}{l}\text { External } \\
\text { fixation }\end{array}$ & $9 \mathrm{mth}$. & $*$ & $\begin{array}{l}\text { Long } \\
\text { plate }\end{array}$ \\
\hline 12 & 42 & $\mathrm{~m}$ & $\mathrm{~L}$ & & & L-plate & $2 \mathrm{y}$ & & \\
\hline 13 & 24 & $\mathrm{~m}$ & $\mathrm{~L}$ & & & L-plate & $2.5 \mathrm{y}$ & & \\
\hline 14 & 18 & $\mathrm{~m}$ & $\mathrm{~L}$ & & & L-plate & $1.8 \mathrm{y}$ & & \\
\hline 15 & 33 & $\mathrm{~m}$ & $\mathrm{~L}$ & & & $\begin{array}{l}\text { External } \\
\text { fixation }\end{array}$ & $1 \mathrm{y}$ & & Plate \\
\hline
\end{tabular}

The interval between primary trauma and surgery till quadricepsplasty was divided into four groups according to the patient history, the mean duration was $19.40 \pm 17.638$ months as shown in table II.

\begin{tabular}{|l|l|l|}
\hline \multicolumn{3}{|c|}{ Table II: Duration of the stiffness in months } \\
\hline Duration( months) & No. & Total \\
\hline $5-10$ & 1 & $7 \%$ \\
\hline $15-20$ & 3 & $20 \%$ \\
\hline $20-25$ & 4 & $27 \%$ \\
\hline$>25$ & 7 & $46 \%$ \\
\hline Total & 15 & $100 \%$ \\
\hline
\end{tabular}

The average preoperative flexion was 28 degrees (ranging from 10 to 50 degrees), and the average follow-up was 6.5 months (range, 3-15 months). The average of flexion gain are 97.67 degrees (range 60-120 degrees). Statistical analysis of significance in this study showed that the preoperative flexion was significantly lower than that measured at all the other observations $(\mathrm{P}=0.001)$ which is highly significant; while the postoperative flexion was significantly lower than intra-operative flexion $(\mathrm{P}=0.005)$. The final results according to the Judet's criteria are presented in the table III. 


\begin{tabular}{|l|l|l|l|l|l|l|}
\hline \multicolumn{7}{|l|}{ Table III: Range of the movements and the final results } \\
\hline Case & Follow-up (mth) & $\begin{array}{l}\text { Pre- } \\
\text { operative } \\
\text { ROM }\end{array}$ & $\begin{array}{l}\text { ROM } \\
\text { during } \\
\text { surgery }\end{array}$ & $\begin{array}{l}\text { Post- } \\
\text { operative } \\
\text { ROM }\end{array}$ & $\begin{array}{l}\text { Final gain } \\
\text { in flexion }\end{array}$ & $\begin{array}{l}\text { Final } \\
\text { result }\end{array}$ \\
\hline 1 & 4 & $10(0-10)$ & 110 & $60(0-60)$ & 50 & Fair \\
\hline 2 & 15 & $35(0-35)$ & 120 & $100(0-100)$ & 65 & Good \\
\hline 3 & 10 & $25(0-25)$ & 140 & $120(0-120)$ & 95 & Excellent \\
\hline 4 & 10 & $25(0-25)$ & 120 & $110(0-110)$ & 85 & Excellent \\
\hline 5 & 10 & $45(0-45)$ & 130 & $120(0-120)$ & 75 & Excellent \\
\hline 6 & 8 & $15(0-15)$ & 110 & $90(0-90)$ & 75 & Good \\
\hline 7 & 6 & $25(0-25)$ & 110 & $80(0-80)$ & 55 & Good \\
\hline 8 & 10 & $20(0-20)$ & 120 & $110(0-100)$ & 90 & Excellent \\
\hline 9 & 5 & $30(0-30)$ & 110 & $75(0-75)$ & 45 & Fair \\
\hline 10 & 3 & $30(0-30)$ & 110 & $90(0-90)$ & 60 & Good \\
\hline 11 & 4 & $30(0-30)$ & 120 & 90 & $\begin{array}{l}\text { Extension } \\
\text { lag }\end{array}$ & \\
\hline 12 & 3 & $50(0-50)$ & 140 & $110(0-110)$ & 60 & Excellent \\
\hline 13 & 6 & $30(0-30)$ & 130 & $120(0-120)$ & 90 & Excellent \\
\hline 14 & 4 & $20(0-20)$ & 130 & $80(0-80)$ & 40 & Good \\
\hline 15 & 3 & $25(0-10)$ & 120 & $110(0-80)$ & 85 & Excellent \\
\hline
\end{tabular}

The average flexion in preoperative period, the average flexion degree that was achieved intra-operative and the definitive flexion gain after more than 3 months follow-up showed that the ranges of the movements were decreased immediately after surgery but with the programs of physiotherapy it increased gradually in most of the patients as shown in figure 1.

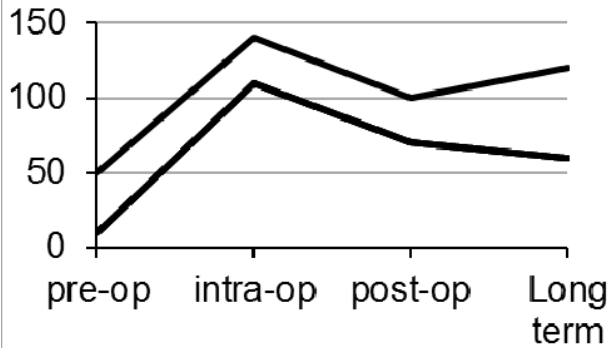

Figure 1: The range of flexion pre-operative, intra-operative and definitive flexion gain.

Seven patients (47\%) got excellent results, 5 patients $(33 \%)$ got good result, while 2 patients $(13 \%)$ got fair result, and 1 patient $(7 \%)$ ended with extension lag as shown in table IV.

\begin{tabular}{|c|c|c|c|}
\hline \multicolumn{4}{|c|}{ Table IV: Final results of the study } \\
\hline & & Frequency & Percentage \\
\hline \multirow[t]{5}{*}{ Judet's criteria } & Excellent & 7 & $47 \%$ \\
\hline & Good & 5 & $33 \%$ \\
\hline & Fair & 2 & $13 \%$ \\
\hline & Extension lag & 1 & $7 \%$ \\
\hline & Total & 15 & $100 \%$ \\
\hline
\end{tabular}


The number and the percentage of group 1 (preoperative flexion $<30^{\circ}$ ) and group 2 (preoperative flexion $>30^{\circ}$ ) from the total number of patients are shown in table $\mathrm{V}$.

\begin{tabular}{|l|l|l|}
\hline \multicolumn{3}{|c|}{ Table V: Frequency and Percentage in groups 1 \& 2} \\
\hline & Frequency & Percent \\
\hline Group 1 & 11 & $73 \%$ \\
\hline Group 2 & 4 & $27 \%$ \\
\hline Total & 15 & $100 \%$ \\
\hline
\end{tabular}

Incidence of patients outcome according to Judet's Criteria regarding preoperative flexion Arch of $<30^{\circ}$ (Group 1) and $30^{\circ}$ and more (Group 2) are shown in table VI.

\begin{tabular}{|c|c|c|}
\hline Judet's Criteria & $\begin{array}{l}\text { Group } 2 \\
(\text { Flexion }>30)\end{array}$ & $\begin{array}{l}\text { Group } 1 \\
(\text { Flexion }<30)\end{array}$ \\
\hline & No. $(\%)$ & No. $(\%)$ \\
\hline Excellent & $2 \quad(50)$ & $5 \quad(50)$ \\
\hline Good & $2 \quad(50)$ & $3 \quad(30)$ \\
\hline Fair & & $2 \quad(2)$ \\
\hline
\end{tabular}

The number of patients in group 1 and group 2 were 15 patients but if we classified those patients according to the Judet's criteria we must exclude one patient because this patient ended with extension lag and it will not be included in this criteria as shown in previous table and figure 2 .

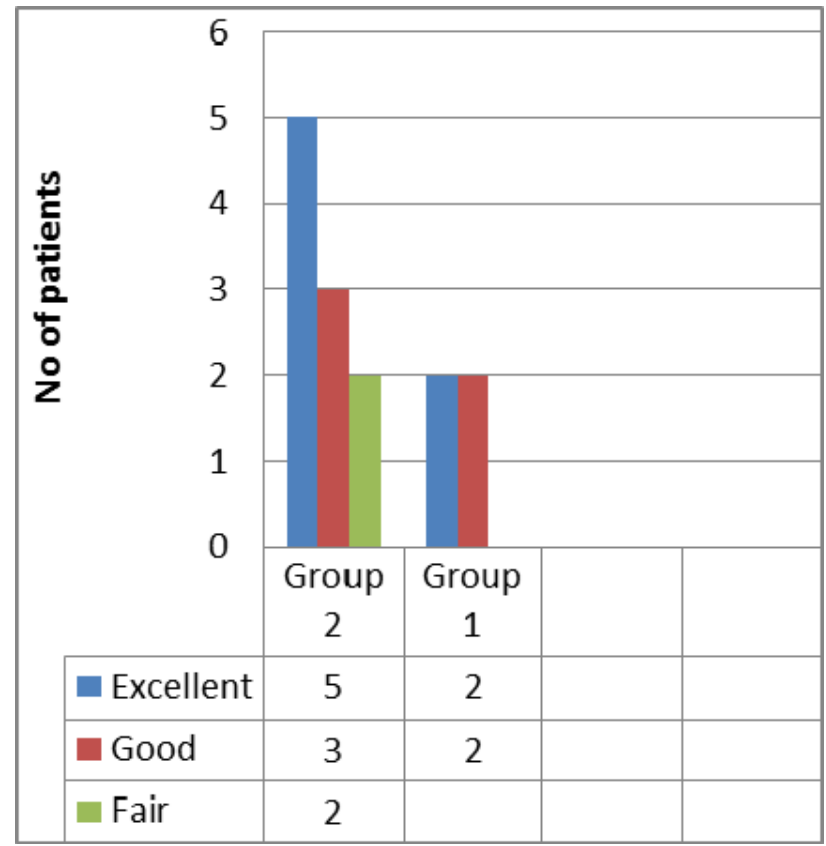

Figure 2: Number and percentage of the patients in each group. 
The patients with previous history of osteomyelitis got a fair result in two patients; one patient got a good result and one patient end up with extension lag. So there is a strong relationship between the history of osteomyelitis and the final results of the quadricepsplasty. The definitive flexion gain was reversibly correlated with the preoperative flexion, with the preoperative interval and directly correlated with the length of the follow-up. Two complications arose related to the Judet procedure; one patient ended with extension lag and another one got small area of skin necrosis which was treated conservatively. The long term range of the movements in all patients is shown in figure 3.

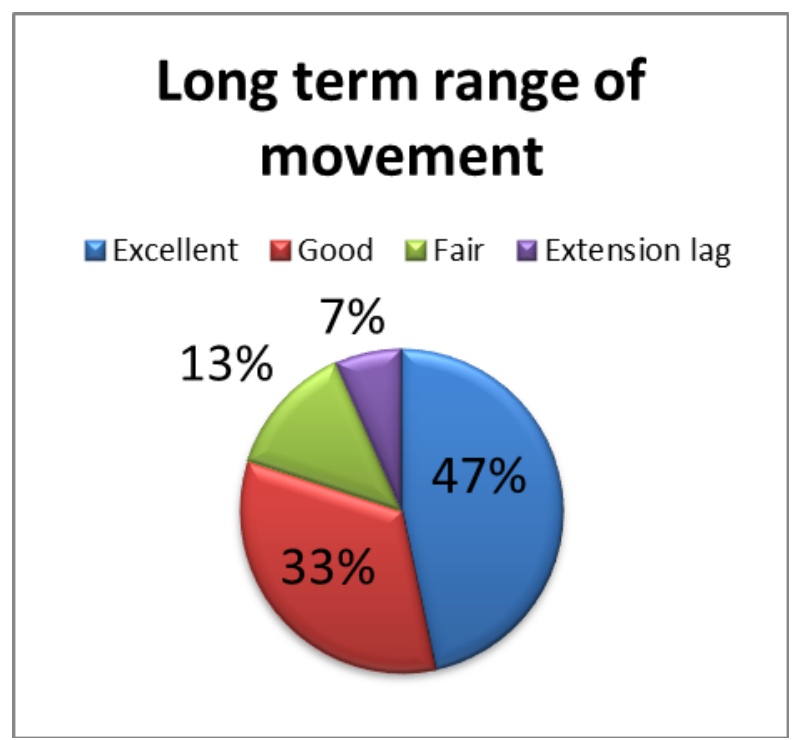

Figure 3: Long term movements

Finally, as a subjective study for all of our patients satisfaction about the outcome in the degrees of flexion gain after history of stiffness, we classify the patients to: worse, fair, good, and very good as shown in figure 4.

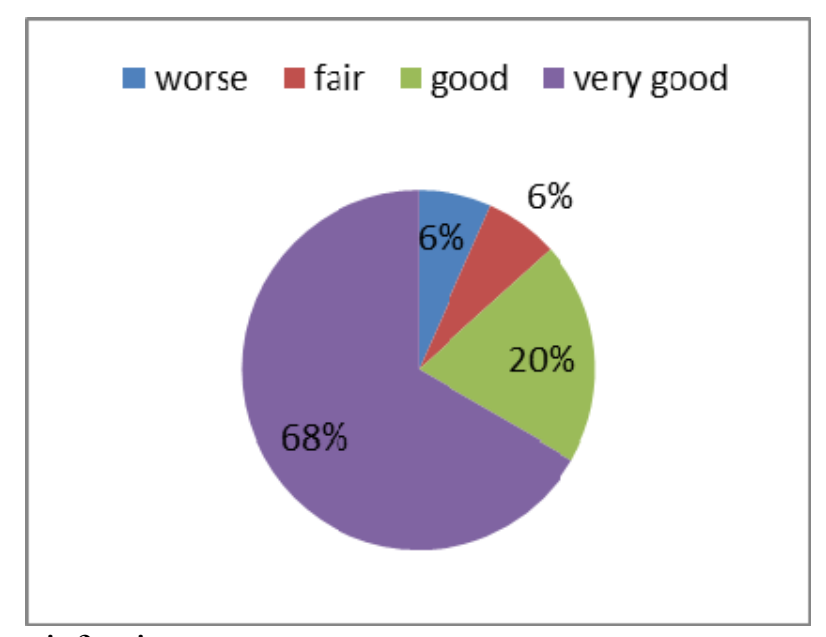

Figure 4: Patient's satisfaction. 


\section{Discussion}

Stiff knee is a serious complication after fracture of the distal femur or other injuries around the knee joints.

The total number of the patients in the study were 15 patients, (12 males and 3 females), all of them were complaining from post-traumatic stiffness in the knee joint during eighteen months time, which is relatively small sample for a study but in comparison with other studies about the same subject, it is similar to the study done by Hahn et al whose total sample size was 20 patients $^{3}$, in other studies done by Masse et al on 21 patients ${ }^{4}$, and another study done by Bellemans et al on 16 patients $^{5}$. while the study that was done by Ali et al was done on 10 patients ${ }^{6}$.

The age of our patients was between 1851 years, the mean age was 35.60 years; when compared with study done by Ebbrahimzadeh et al, the age of patients ranged between 17 years and 65 years ${ }^{7}$. In an another study done study done by Hahn et al, The mean age of the patients was 37 years $(18-64)^{3}$, also it was very close to our patients number. Another study was done by Masse et al, the average age was 29.57 years (range, 1842 years) ${ }^{4}$ and was similar to our results. All of these finding reveals that this age group are more vulnerable for trauma and have more incidence of stiffness.

The mean interval between the initial operation and quadricepsplasty was $19.40 \pm 17.638$ months (3-72 months) for our patients, while the interval period in a study done by Hahn et al, the mean interval between the initial operation and quadricepsplasty was 28 months (14-60 months) ${ }^{3}$, these results are very close to our findings. Another study done by Masse et al, the average preoperative interval was 35.5 months (range, 10-88 months $)^{4}$, which was longer than that of our patients. In a study done by Ebbrahimzadeh et al, the patients were operated upon in an average $6.9 \pm 3.6$ months (range, 4-24 months) after first initial surgery, which was shorter than that of our patients, while the study that was done by Daoud et al showed that patients were operated upon in long period of interval (6 months - 21 years) ${ }^{8}$ which are commensurate with our study. Four patients $(27 \%)$ in our study had previous history of osteomyelitis which affect significantly the final result of flexion gain. In a study done by Masse et al on 21 patients, they found that three patients $(14 \%)$ had osteomyelitis ${ }^{4}$ which was relatively higher in our patients. Another studies done by Ebbrahimzadeh et al on 40 patients and a study done by Daoud showed that all patients had no history of osteomyelitis ${ }^{7,8}$.

The range of movement preoperativly for our patients was $10-50^{\circ}$ with a mean $28 \pm 10.488$ degrees, when compared with a study done by Hahn et al, the mean flexion contracture was $7.0^{\circ}$ (0 to 30$)$ with active flexion to $50.0^{\circ}$ (5 to 80 ). The mean range of movement was thus $43.0^{\circ}$ $(5 \text { to } 80)^{3}$, which was higher than that of our patients. Another study done by Ebbrahimzadeh et al, the preoperative flexion was $0-90^{\circ}$ with average of flexion $\left(30.75 \pm 28.54^{\circ}\right)^{7}$, which was higher than that of our patients. In a study done by Masse et al, the range of the flexion was $5-50^{\circ}$ pre operatively ${ }^{8}$. these results are very close to our findings.

We recorded two complications in our patients; one patient with extension lag and other with small area of skin necrosis treated conservatively with daily dressing and antibiotics. While the study done by Hahn et al, one patient had a deep infection which resolved after wound care and intravenous antibiotics ${ }^{3}$. In a study done by Masse et al, the complications related to the Judet procedure included deep sepsis (2 cases), intraoperative rupture of the quadriceps tendon (1 case), 
skin necrosis ( 1 case), and fracture of the lateral femoral condyle (1 case $)^{4}$, which was worse than that of our patients. Another study done by Ebbrahimzadeh et al, the complications occur in this study included two cases $(5 \%)$ of superficial infection and one case $(2.5 \%)$ with patellar fracture ${ }^{7}$. However, the results of Ali et al included two patients had postoperative complications, one patient suffer from hematoma and developed infection, and a minimal extension lag (10 degrees ) developed in one patient ${ }^{6}$.

In this prospective study the included patients are with a minimum of a 3 months and maximum 15 months of follow-up, the mean range of follow up was $6.5 \pm 3.61$ months. Due to difficulty in following up our patients, we found that our follow up was short if compared with other studies. In a study done by Hahn et al, the patients were followed for a mean duration of 35 months (24 to 52) ${ }^{3}$ which was longer than that of our study. Another study done by Masse et al, the average follow-up was 101.0 months (range, 21-204 months) ${ }^{8}$, which was longer than that of our study. Another study done by Ebbrahimzadeh et al showed that the average follow-up was 17.5 months (range, 12-24 months) ${ }^{7}$, which was longer than that of our study duration. A study done by Daoud et al showed that all patients were followed up for $24 \mathrm{months}^{8}$ which was longer than that of our study duration.

In our study, the final results of the patients according to the Judet's criteria were $47 \%$ with excellent range $\left(>100^{\circ}\right)$ flexion, $(33 \%)$ with good results $\left(80-99^{\circ}\right)$, $(13 \%)$ with fair results $\left(50-79^{\circ}\right)$ and $(7 \%$ ) have extension lag. In a study done by Masse et al on 21 patients, they found excellent results in eight cases $(38.10 \%)$, good in nine $(42.86 \%)$, and fair in four $(19.05 \%)$ with zero poor results ${ }^{4}$, and these results are commensurate with our study. Another study done by
Ebbrahimzadeh et al on 40 patients found 9 patients $(22.5 \%)$ achieved excellent, 27 patients $(67.5 \%)$ good, 2 patients $(5 \%)$ fair, and 2 patients $(5 \%)$ poor results ${ }^{7}$, and when the results of this study are compared with our results, a highly percentage of good results were found but also $5 \%$ of the patients ended with poor outcome. However, the results of Ali et al study are; $20 \%$ excellent, $70 \%$ good and $10 \%$ with fair results ${ }^{6}$. Another study done by Daoud et al ended with $85 \%$ of the patients with good or excellent and $4 \%$ with poor results ${ }^{8}$. Finally if we compare our results with that of other studies for those who performed Judet's quadricepsplasty, we can say that the main factors that affect the end results of flexion gain are; previous history of osteomyelitis, duration of elapsed time between the primary injuries and quadricepsplasty, duration of the physiotherapy and follow-up.

Conclusion:

Our study showed that Judet quadricepsplasty successfully increases flexion range with less impairment of quadriceps function. Familiarity with this technique might lower the surgeon's threshold for considering quadricepsplasty in patients with severe knee ankylosis after severe femoral fractures and in particular after a prolonged period of external fixation or other causes of stiffness. The Judet technique of quadricepsplasty offers the advantages of a controlled, sequential release of the components limiting knee flexion and a reduced potential for iatrogenic quadriceps rupture or extension lag. Patients with history of multiple injuries, long period of stiffness, severe soft tissue scar, or specially those with previous history of osteomyelitis are more probably not to achieve an excellent results or end with other complications like extension lag. The definitive flexion 
gain did not correlate with either patient age or sex whereas it was reversibly correlated with the preoperative flexion, with the preoperative interval and directly correlated with the length of follow-up.
Our research has shown that, even the first procedure of Judet's quadricepsplasty performed in 1956, the Judet procedure still gives a reproducible amount of good results.

\section{References}

1. Nicoll EA: Quadricepsplasty in the treatment of stiff knee following trauma. Postgrad Med J. 1964; 40: 521-526

2. Rich K: What is a stiff knee? http://www.localhealth.com/article/stiff-knee.[accessed $11 / 07 / 2012]$.

3. Hahn S.B, Lee W.S, Han D.Y: A modified Thompson quadricepsplasty for the stiff knee. The Journal Of Bone and Joint Surgery. 2000;82-B:992-995.

4. Masse, A, Biasibetti A., Demangos J., Dutto E., Pazzano S., and Gallinaro P.: The Judet Quadricepsplasty: Long-Term Outcome of 21 Cases. The Journal of Trauma. 2006;61:358 -362.

5. Bellemans J., Steenwerckx A., Brabants K., Vector J., Lammens J., Fabry G.: The Judet Quadricepsplasty a retrospective study of 16 cases. ACTA Orthopaedica Belgica, 1996:. 62-66.

6. Ali AM, Villafuerte J, Hashmi M, Saleh M.: Judet's quadricepsplasty, surgical technique, and results in limb reconstruction: Clinical Orthopaedics Related Research. 2003 Oct;(415):214-220

7. Ebbrahimzadeh MH., Birjandi-Nejad A, Ghorbani S, and Khorasani MR. : A Modified Thompson Quadricepsplasty for Extension Contracture Resulting From Femoral and Periarticular Knee Fractures. The Journal of Trauma Injury, Infection, and Critical Care. Volume 68, Number 6, June 2010:1471- 1475.

8. Daoud H, O'Farrell T, Cruess RL.: Quadricepsplasty: The Judet technique and results of six cases. J Bone Joint Surgery. 1982;64:194-197. 